\title{
CUANTIFICACIÓN DE LAS CONCENTRACIONES DE METALES PESADOS EN TEJIDOS DE PECES Y CRUSTÁCEOS DE LA LAGUNA DE UNARE, ESTADO ANZOÁTEGUI, VENEZUELA.
}

\author{
Quantification of the Concentrations of Heavy Metals in Tissues of Fish and Crustaceans \\ of the Unare Lagoon, Anzoateguí State, Venezuela.
}

\author{
Aristide Márquez ${ }^{1}$, William Senior ${ }^{1}$, Ivis Fermín, Gregorio Martínez ${ }^{1}$, Julián Castañeda ${ }^{1}$ y Ángel González ${ }^{2}$ \\ ${ }^{1}$ Departamento de Oceanografía, Instituto Oceanográfico de Venezuela, Universidad de Oriente, Núcleo de Sucre. \\ Av. Universidad, Cerro Colorado. Cumaná, estado Sucre, Venezuela. TIf. (058) 02934002119; Telf. movil. 04147754638. \\ E-mail: aristide@sucre.udo.edu.ve; aristd@gmail.com \\ 2 Instituto Limnológico, Universidad de Oriente, Núcleo de Bolívar. Caicara del Orinoco, estado Bolívar.
}

\begin{abstract}
RESUMEN
Se analizó por Espectrofotometría de Absorcion Atomica de llama el contenido de $\mathrm{Fe}, \mathrm{Mn}, \mathrm{Cu}, \mathrm{Cr}, \mathrm{Ni}, \mathrm{Zn}, \mathrm{Cd}$ y $\mathrm{Pb}$ en tejidos musculares de peces y crustáceos de la laguna de Unare, estado Anzoátegui, Venezuela. Adicionalmente, se determinaron los niveles en el material en suspension del agua y en el sedimento para detectar posibles impactos en el ecosistema. En el agua, las concentraciones medias de metales fueron bajos $(0,104-0,53 \mu \mathrm{mol} / \mathrm{L} \mathrm{Fe} ; 0,004-0,06 \mu \mathrm{mol} / \mathrm{L} \mathrm{Mn;} \mathrm{0,002-0,028}$ $\mu \mathrm{mol} / \mathrm{L} \mathrm{Zn} ; 0,004-0,012 \mu \mathrm{mol} / \mathrm{L} \mathrm{Cr}$; no detectado-0,011 $\mu \mathrm{mol} / \mathrm{L}$ $\mathrm{Ni}$ y no detectado- 0,001 $\mu \mathrm{mol} / \mathrm{L} \mathrm{Cd}$ ). En el sedimento se evidencia intervención antropogénica con valores medios que decrecen $\mathrm{Mn}(516,37)>\mathrm{Zn} \quad(127,49)>\mathrm{Ni} \quad(52,41)>\mathrm{Cr} \quad(51,69)>\mathrm{Cu}$ $(41,13)>\mathrm{Pb}(29)>\mathrm{Cd}(1,51 \mu \mathrm{g} / \mathrm{g})$ y que superan los niveles establecidos para sedimentos no contaminados. En los tejidos de los organismos se detectó la presencia de metales tóxicos como el plomo y cadmio que superan los 0,16 y $0,04 \mu \mathrm{g} / \mathrm{g}$, respectivamente, al igual que el zinc que alcanza niveles elevados que sobrepasan $17 \mu \mathrm{g} / \mathrm{g}$ en la mayoría de las especies. Las pruebas estadísticas de ANOVA $(P<0,05)$ indican discrepancias en las concentraciones metales en los tejidos por los diferentes géneros y especies, al igual que en los valores de los individuos de la misma especie (Cathorops spixii) que habitan dentro y fuera de la laguna. Los niveles son mayores en los habitantes del interior de la laguna evidenciando fenómenos de bioacumulación. La investigación confirman un progresivo deterioro ambiental de la laguna y de las especies ícticas de este ecosistema que son comercializadas por las poblacio-
\end{abstract}

Recibido: 02 / 05 / 2006. Aceptado: 02 / 05 / 2007. nes aledañas a la laguna, las cuales sustentan su economía de su explotación pesquera.

Palabras clave: Peces, tejidos, metales, laguna costera, degradación.

\section{ABSTRACT}

The content of $\mathrm{Fe}, \mathrm{Mn}, \mathrm{Cu}, \mathrm{Cr}, \mathrm{Ni}, \mathrm{Zn}, \mathrm{Cd}$ and $\mathrm{Pb}$ in muscle tissues of fish and crustaceans from the Unare lagoon (Laguna de Unare) in the state of Anzoátegui, Venezuela, was analyzed by flame Atomic Absorption Spectrometry. The levels of these metals present in suspended material of the water and in sediments were also determined in order to detect possible impact on the ecosystem. The mean concentrations in the water were low (0.104-0.53 $\mu \mathrm{mol} / \mathrm{L} \mathrm{Fe}$; 0.004-0.06 $\mu \mathrm{mol} / \mathrm{L} \mathrm{Mn;0.002-0.028}$ $\mu \mathrm{mol} / \mathrm{L}$ Zn; 0.004-0.012 $\mu \mathrm{mol} / \mathrm{L} \mathrm{Cr}$; undetectable-0.011 $\mu \mathrm{mol} / \mathrm{L}$ $\mathrm{Ni}$ and undectable-0.001 $\mu \mathrm{mol} / \mathrm{L} \mathrm{Cd}$ ). In the sediments, evidence was found of anthropogenic intervention with mean values in decreasing order of $\mathrm{Mn}(516.37)>\mathrm{Zn}(127.49)>\mathrm{Ni}$ $(52.41)>\mathrm{Cr}(51.69)>\mathrm{Cu}(41.13)>\mathrm{Pb}(29)>\mathrm{Cd}(1.51 \mu \mathrm{g} / \mathrm{g})$, all of which are greater than established levels for uncontaminated sediments. Toxic metals were detected in the examined organisms, such as lead and cadmium with levels above 0.16 and $0.04 \mu \mathrm{g} / \mathrm{g}$, respectively, and zinc with levels greater than $17 \mu \mathrm{g} / \mathrm{g}$ in the majority of the species. ANOVA statistical tests $(P<0.05)$ show discrepancies in the concentrations or the metals in the tissues of the different genera and species, as well as in the values for individuals of the same species (Cathorops spixii) which live inside and outside of the lagoon. The levels are higher in those which live within the lagoon, 
Cuantificación de las concentraciones de metales pesados en peces de Unare, Anzoátegui, Venezuela / Márquez, A. y col.

which indicates bioaccumulation processes. This study confirms that the lagoon and its biota have suffered a progressive and important deterioration inasmuch as the neighboring population relies on the commercialization of the fish and crustaceans for their economic stability.

Key words: Fish, tissues, metals, coastal lagoon, degradation.

\section{INTRODUCCIÓN}

Las actividades humanas tienen un impacto considerable en las comunidades de peces de las lagunas litorales y estuarios. Proyectos agrícolas, acuícolas, industriales y de ingeniería alteran la forma y naturaleza de estos ecosistemas; las descargas domésticas e industriales agregan una contaminación adicional que ejercen una fuerte presión sobre las actividades pesqueras, teniendo un efecto significante en la abundancia y estructura de la comunidad [8]. Existe una serie de ventajas de usar las comunidades de peces en los estudios de impacto medioambientales debido a la alta movilidad de muchas especies, la velocidad de procesar las muestras y el hecho que ellos permiten un acercamiento multitrófico $[7,8]$.

Algunos de los ecosistemas que figuran entre los de mayor productividad biológica son los lagunares costeros, los cuales se caracterizan por su productividad y por una marcada fragilidad y vulnerabilidad frente a la variedad de presiones antropogénicas que se ejercen sobre ellos. En Venezuela los estudios sobre el contenido de metales en lagunas han sido realizados mayoritariamente en sedimentos de aquellas que se encuentran en la zona marino-costeras en donde hay una actividad pesquera de relativa importancia [13]. La laguna de Unare es uno de los cuerpos acuáticos más importantes en Venezuela desde el punto de vista biológico y pesquero [19, 25].

La laguna de Unare está asociada ecológicamente con el río Unare, y su ictiofauna está representada por 27 familias, 37 géneros y 43 especies, donde los peces pueden ser catalogados en tres grupos: sedentarios, que cumplen todo su ciclo vital en la laguna, emigrantes estacionales, que entran a la laguna durante ciertos meses del año y los visitantes ocasionales [25]. La laguna es un centro de una notoria actividad pesquera artesanal basada en camarones y peces. Se estima que entre 30.000 personas dispersas en los pueblos y caseríos ubicados en su entorno (Boca de Uchire, El Hatillo, La Cerca, Boca Chávez, Nuevo Unare, San Juan, Punto Lindo, etc. viven directa e indirectamente de esta actividad [25].

No obstante, debido a las actividades antropogénicas se ha registrado un deterioro ecológico que está contribuyendo a la desaparición de su recurso pesquero [25]. Esta problemática existente en la laguna ha sido estudiada por más de 30 años, realizándose numerosos trabajos que están documentados [13, 19, 24, 25, 28, 29, 31, 33, 41]. Actualmente, uno de los problemas más importantes para la ictiofauna de la laguna de Unare reside en los asentamientos urbanos aledaños a su margen y en el manejo de los volúmenes de agua dulce que ingresan a ella desde el río Unare, el cual se ha hecho sin conocimiento técnico adecuado.

La laguna de Unare posee intrínsecos valores ecológicos representados por su calificación como: zonas de humedales (manglares), refugio de fauna silvestre, reservorio de especies estuarinas, refugio de aves migratorias y albergue de importantes factores de biodiversidad; adicionalmente el ecosistema posee valores paisajísticos singulares. Además la laguna constituye un valioso recurso en la importante actividad económica de pesquería artesanal realizada en la localidad, que pudiera ser afectada sí la polución química alcanzara a la biota a través de sedimentos contaminados, ya que Yilmaz [51] ha determinado que los peces de bahías son susceptibles de ser afectadas por algunos metales pesados ( $\mathrm{Fe}, \mathrm{Cu}, \mathrm{Ni}, \mathrm{Cr}$, $\mathrm{Pb}$ y $\mathrm{Zn})$.

Los metales pesados son contaminantes que entran al sedimento desde los cuerpos de aguas produciéndose un aumento progresivo de sus concentraciones en el tiempo y posterior bioacumulación de organismos que forman parte de esos ecosistemas [37]. Estos elementos, en comparación con otros contaminantes, no son biodegradables y sufren un ciclo ecológico global en el cual las aguas naturales son las principales vías, siendo críticos los efectos negativos que ellos ejercen, debido a que pueden causar graves daños a nivel celular dada su capacidad para desnaturalizar proteínas, ser asimilados por el fitoplancton y organismos filtradores e incorporados a la cadena alimenticia provocando graves alteraciones ecológicas y biológicas, no solo al ecosistema, sino a los humanos [15].

En vista de que la laguna de Unare representa un medio de valiosa importancia para el desarrollo de algunas especies de peces y crustáceos y que se carecen de estudios de metales pesados en los organismos ícticos de este importante ecosistema, se realizó un estudio de cuantificación de las concentraciones de metales pesados en los tejidos de algunas especies de peces y crustáceos que viven dentro de la laguna, ya que los tejidos musculares son analizados rutinariamente en los programas de monitoreo en los ecosistemas marinos por la tendencia que presentan para acumular contaminantes [30].

\section{MATERIALES Y MÉTODOS}

\section{Área de estudio}

La laguna de Unare tiene una superficie variable según la época del año. Las dimensiones máximas fueron $21,5 \mathrm{Km}$ de longitud y anchura $5,5 \mathrm{Km}$, aproximadamente. La superficie del agua, según la referencia, cubría un área aproximada de $65,5 \mathrm{Km}^{2}$ [49]. El tributario fundamental de agua dulce hacia la laguna, lo constituye un caño del río Unare que ingresa por la parte oriental de la laguna, mientras que por la parte occidental y central están los ríos Chávez y Cautaro (FIG. 1). El río Chávez constituye el segundo tributario en cuanto al volumen 


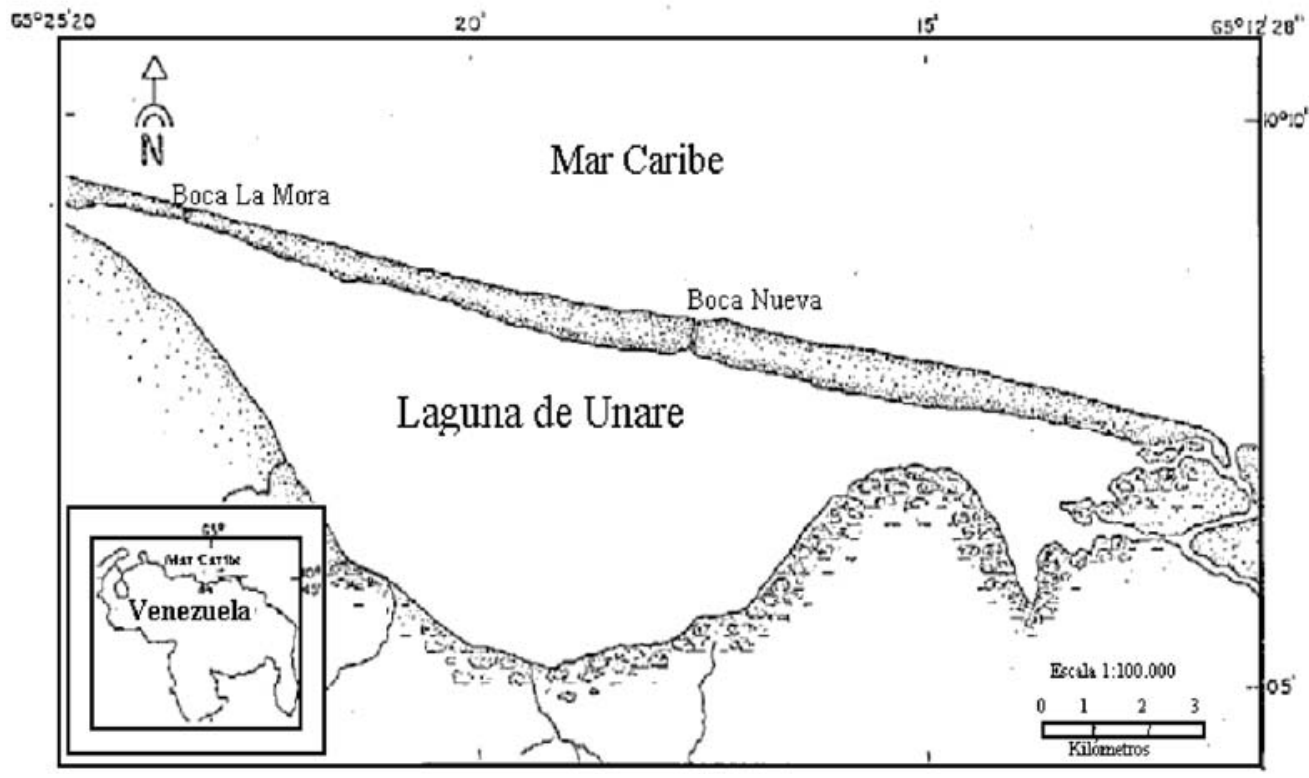

FIGURA 1. LAGUNA DE UNARE, ESTADO ANZOÁTEGUI, VENEZUELA / UNARE LAGOON, ANZOÁTEGUI STATE, VENEZUELA.

de afluentes líquidos que son vertidos al ecosistema. En la barra arenosa que separa el mar de la laguna existen tres bocas (Mora, Nueva, y la del río Unare) que se cierran cíclicamente en función de la dinámica sedimentaria que ocurre en la línea costera. Cabe destacar que, en la barra están ubicados varios centros residenciales, tanto del tipo tradicional como turísticos. Por otro lado, la batimetría, de la laguna de Unare, registra variaciones en función de la época del año.

\section{Muestreo de agua y análisis del material en suspensión}

Con el propósito de determinar las concentraciones de metales presentes en el material suspendido del agua se recolectaron 14 muestras en un muestreo de 24 horas en la laguna de Unare en octubre 2002 (época de lluvia). La recolección de las muestras se realizó de 2 en 2 horas, comenzando el 25 de octubre a las 12,30 del medio día hasta las 8,30 am del día siguiente. Las muestras fueron recolectadas, utilizando envases de polietileno previamente lavados con ácido nítrico al 10\%. Dos litros de muestra fueron filtrados en un equipo Millipore (EUA), utilizando membranas filtrantes de celulosa tipo HA con poros de 0,45 $\mu \mathrm{m}$ de diámetro. El material retenido en el filtro fue tratado por digestión con una mezcla de ácido nítrico y clorhídrico concentrados para obtener los metales en fase acuosa [18]. Las medidas fueron hechas por Espectrofotometría de Absorción Atómica con llama de aire-acetileno utilizando un equipo Perkin Elmer 3100 (EUA).

\section{Muestreo de sedimentos y análisis}

Se recolectaron 24 muestras de sedimentos superficiales en un solo muestreo, utilizando una draga tipo Eckman (EUA) de 0,02 m2 de área. Con el apoyo de una paleta plástica, las muestras se colocaron en frascos de polipropileno de $250 \mathrm{~mL}$ de capacidad, lavados con una solución ácida $(\mathrm{HCl}$
$1 \mathrm{~N}$; Merck) y agua desionizada, calidad Nanopure. Los envases con los sedimentos fueron previamente rotulados y luego congelados a $-20^{\circ} \mathrm{C}$, hasta su procesamiento. Los sedimentos fueron secados a $60^{\circ} \mathrm{C}$ en una estufa $P$ Selecta (EUA), y luego pulverizados en un mortero de porcelana. $2 \mathrm{~g}$ de muestra fueron pesados en una balanza analítica marca Denver Instrument M-10 (EUA) con precisión de 0,0001g, y luego digestadas con una mezcla de ácido nítrico y ácido perclórico, 3:1, para lograr la mineralización total de los sedimentos. Para tal fin las muestras fueron colocadas en un Digestor de Microondas Microdigest 401 de Prolabo (Francia), a $110^{\circ} \mathrm{C}$, por espacio de 30 minutos. Posteriormente todas las muestras fueron filtradas en filtros de papel Whatman $N^{\circ} 542$ hasta obtener un volumen de filtrado de $25 \mathrm{~mL}$. Las medidas fueron hechas por Espectrofotometría de Absorción Atómica con llama de aire-acetileno utilizando un equipo Perkin Elmer 3100 (EUA).

Toda el agua utilizada, tanto en la preparación de reactivos, curvas de calibración y blancos de reactivos, fue agua desionizada altamente pura (agua calidad NANOPURE de conductividad de $18 \mathrm{M} \Omega / \mathrm{cm}$ ). Esto fue alcanzado con un sistema NANOPURE UV, Marca Barnstead (EUA). Al mismo tiempo, el material volumétrico de vidrio utilizado en el laboratorio fue de Clase A y los reactivos de Clase Analítica ultra pura.

\section{Toma de muestras de organismos y especies estudiadas}

Se recolectaron 28 ejemplares de Lisa Cabezona (Mugil curema), 47 Lisa criolla (Mugil gaimardianus, DESMAREST, 1831), 26 de Lebranche (Mugil liza, VALENCIENNES, 1836), 36 de Macabí (Elops saurus, LINNAEUS, 1766), 23 de Bagre negro (Cathorops spixii, AGASSIZ, 1829, 32 de Róbalo (Centropomus undecimali; BLOCH, 1792), y 93 del crustaceo Penaeus schmitti en el interior de laguna de Unare, mediante la pesca directa en dos muestreos, realizados el 25 de octubre 
Cuantificación de las concentraciones de metales pesados en peces de Unare, Anzoátegui, Venezuela / Márquez, A. y col.

2002 y el 20 de septiembre 2003. Adicionalmente se recolectaron en la misma fecha, 19 ejemplares de Cathorops spixii fuera de la laguna, con el fin de realizar comparaciones de los niveles de metales en los tejidos de los peces que habian dentro y fuera de este cuerpo de agua. Para la captura de los peces se utilizó una red de ahorque de malla de luz de $7 \mathrm{~cm}$ y para los camarones una de $2 \mathrm{~cm}$. Los peces y camarones capturados durante cada muestreo fueron colocados en bolsas plásticas antes de ser conservados en cavas con hielo y ser trasladados al laboratorio.

La identificación taxonómica para el genero Mugil es sencilla cuando se trata del Lebranche, es fácil de reconocer por sus grandes escamas y forma más alargada del cuerpo, mientras que en las otras dos especies de Lisa es difícil su identificación por la similaridad de los caracteres merísticos; sin embargo, los pescadores de la laguna las diferencian porque en fresco y en tallas adultas la Lisa Cabezona presenta el iris blancuzco mientras que la Lisa Criolla lo tiene entre amarillo y anaranjado [19].

\section{Preparación de las muestras}

En el laboratorio, las muestras fueron lavadas con agua desionizada, posteriormente se extrayeron los tejidos musculares de los peces por encima de la línea lateral y a nivel del inicio de la aleta dorsal, utilizando un cuchillo limpio de acero inoxidable. En los camarones, los tejidos fueron disecados después de remover las viseras y las conchas. Los cortes fueron colocados el bolsas de poliestileno y congelados, a $-20^{\circ} \mathrm{C}$ hasta la realización de los respectivos análisis, según la metodología descrita en Wood y Van Vleet [50]. Con los tejidos extraídos se formaron pool de 3 organismos para cada una de las especies de peces y de 5 para los camarones, así se obtuvieron las muestras finales que fueron analizadas.

\section{Análisis de laboratorio}

Las muestras fueron disecadas hasta peso constante a $80^{\circ} \mathrm{C}$ utilizando una estufa $P$ Selecta (EUA), maceradas en un mortero de porcelana y homogenizadas. $2 \mathrm{~g}$ de muestra seca por triplicado fueron tratados con ácido nítrico concentrado ultrapuro (Merck) [52] y analizados por Espectrofotometría de Absorción Atómica con llama de aire-acetileno y corrección de fondo de deuterio, utilizando un equipo Perkin Elmer 3100 (EUA). Los patrones de calibración y los blancos recibieron el mismo tratamiento.

\section{Eficiencia analítica de los análisis}

Para chequar la calidad analítica de los datos obtenidos del análisis del sedimento se utilizó un patrón certificado por la Enviromental Resource Associates: Catálogo número 540, lote 237 (Priority Pollutn/CPL. Soil; Canada), mientras que la eficiencia analítica del análisis del tejido de los organismos, fue chequeada usando un material estándar de referencia de Metilus edulis, BCR 278 (EUA).

\section{Análisis estadísticos}

Para validar los datos y determinar diferencias en las concentraciones de metales en los tejidos de las diferentes especies, se aplicó la pruebas de Factor de Kruskal-Wallis de Análisis de Varianza de una vía [44], probándose la significancia a un nivel $P<0,05$. Se utilizó adicionalmente, la prueba de rango multiple Student-Newman-Keuls un nivel del $\mathrm{P}<0,05$ para identificar los grupos homogeneos [44]. Se realizaron pruebas similares para determinar la existencia de variaciones en las concentraciones de metales entre ejemplares de la especie Cathorops spixii, capturados dentro y fuera de la laguna, específicamente en la zona marina. En todos los análisis estadísticos de ANOVA se practicó la prueba de Cochran [44] para chequear la homogeneidad de las varianzas. Los análisis computarizados de toda la estadística fue realizada utilizando el paquete Statgraphics Plus 4,1 (EUA). Para establecer la existencia o no de contaminación por metales pesados en los sedimentos de la laguna de Unare, se realizaron comparaciones con los niveles propuestos en el libro de texto de Sadid [37].

\section{RESULTADOS Y DISCUSIÓN}

\section{Metales en el material en suspensión}

En el agua (FIG. 2), las concentraciones de todos los metales fueron bajas. Sin embargo, los valores fueron superiores durante las horas nocturnas, probablemente por la degradación de la materia orgánica del sedimento durante la noche, la cual libera metales a la columna de agua, estas observaciones corroboran las observaciones de Fermín [13], quien señala que durante la noche, las concentraciones de oxígeno disuelto disminuyen en el agua, porque es utilizado en la oxidacion de la materia organica. Los niveles mínimos y máximos en el agua se distribuyeron en el siguiente orden: no detectado- 0,001 $\mu \mathrm{mol} / \mathrm{L} \mathrm{Cd}, 0,004-0,012 \mu \mathrm{mol} / \mathrm{L} \mathrm{Cr}$; 0,0012-0,0075 $\mu \mathrm{mol} / \mathrm{L} \mathrm{Cu} ; 0,104-0,53 \mu \mathrm{mol} / \mathrm{L} \mathrm{Fe}$; 0,002 -0,0078; 0,004-0,06 $\mu \mathrm{mol} / \mathrm{L} \mathrm{Mn} ;$ no detectado-0,011 $\mu \mathrm{mol} / \mathrm{L} \mathrm{Ni}$; no detectado para el plomo y 0,002-0,028 $\mu \mathrm{mol} / \mathrm{L} \mathrm{Zn}$.

El Cd es un elemento altamente tóxico especialmente en su forma $\mathrm{Cd}^{2+}$ Sin embargo, son consideradas las actividades antropogénicas como la principal fuente de ingreso a los sistemas acuáticos [40]. En aguas oceánicas las concentraciones de Cd están en el orden de 1,78 × $10^{-4}-1,04 \times 10^{-4} \mu \mathrm{mol} / \mathrm{L}$ [6] y en las naturales varían por debajo de $8,74 \times 10^{-4} \mu \mathrm{mol} / \mathrm{L}$. La legislación venezolana establece valores límites de cadmio de $1,75 \mu \mathrm{mol} / \mathrm{L}$ para las aguas de descargas al medio marinocostero y valores de $0,044 \mu \mathrm{mol} / \mathrm{L}$ para las aguas destinadas al consumo humano. Los valores determinados en el agua de la laguna de Unare son inferiores a estos niveles.

Los niveles de cromo, en agua de mar se encuentra en un rango de 0,001-0,005 $\mu \mathrm{mol} / \mathrm{L}$. La forma estable y más tóxica del $\mathrm{Cr}$ es el hexavalente, pero proporciones significantes de $\mathrm{Cr}$ (III) está presente enlazado con algunos componentes orgánicos [21]. En las aguas destinadas a consumo humano, la 


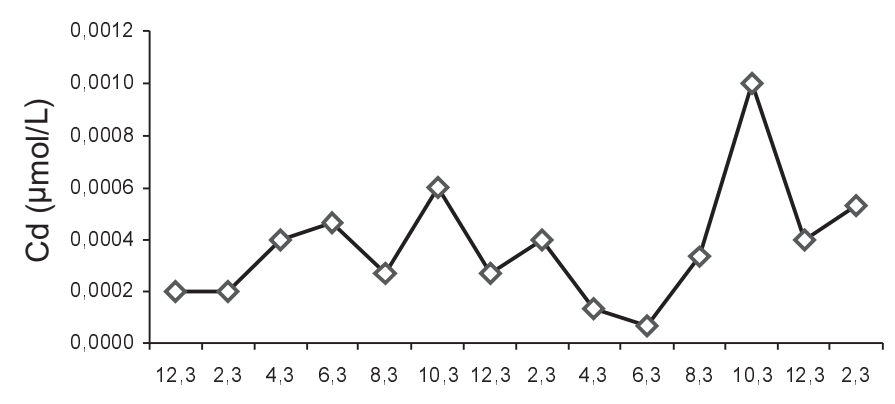

Hora

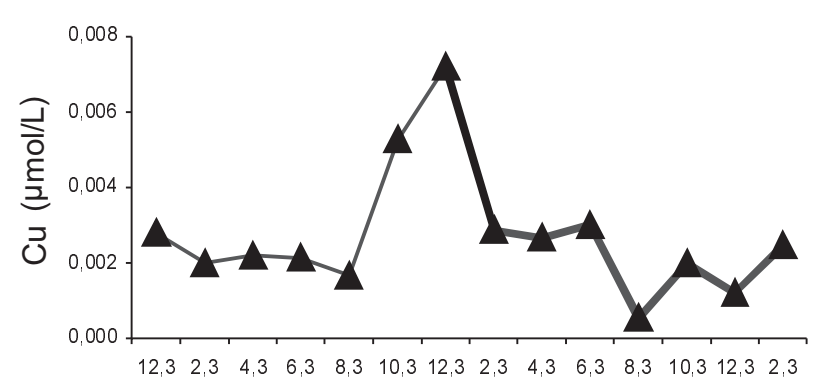

Hora

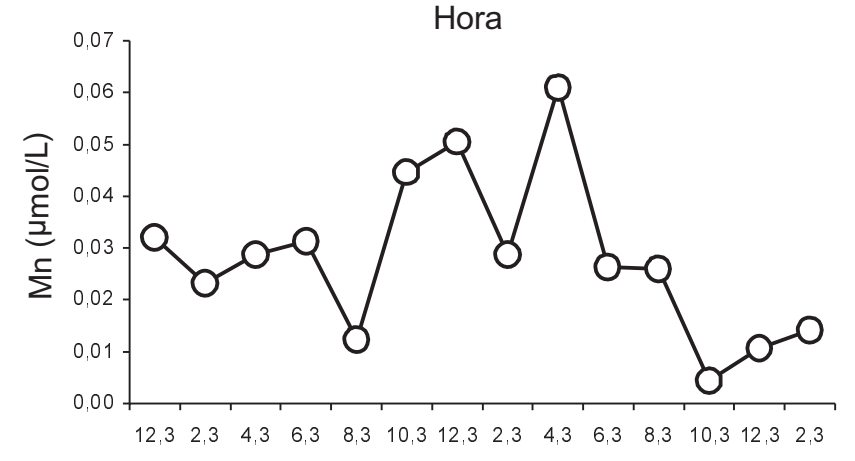

Hora
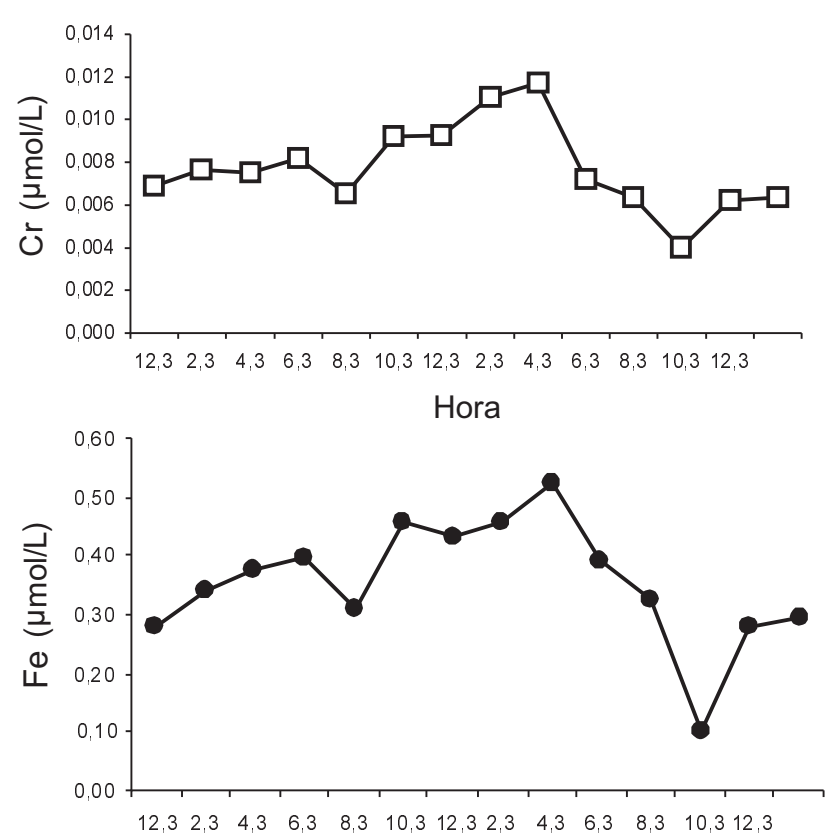

Hora

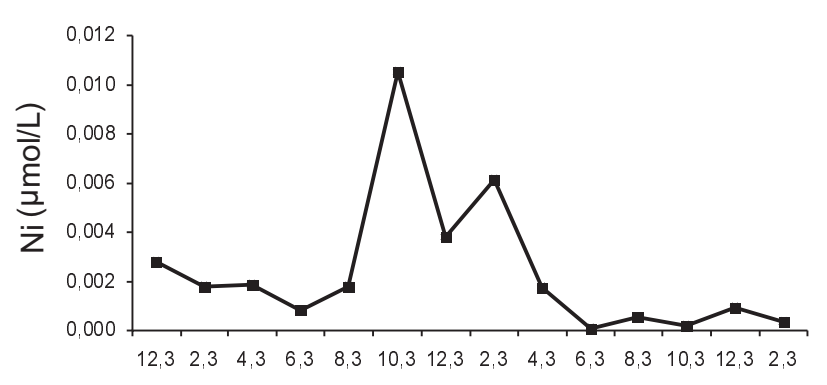

Hora

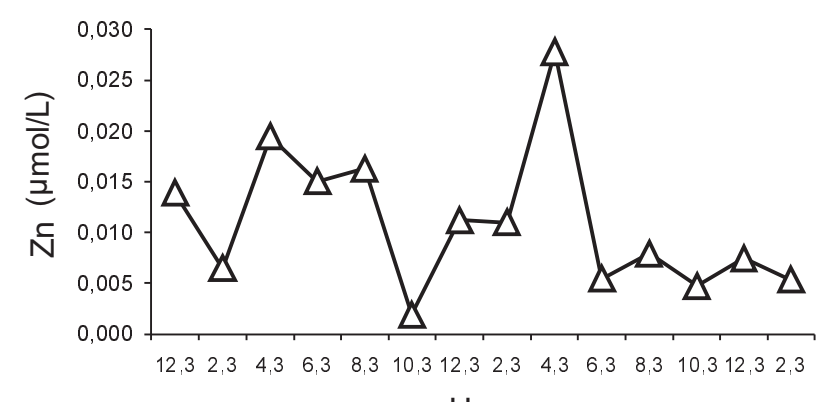

Hora

FIGURA 2. SERIE DE TIEMPO DE LAS CONCENTRACIONES ( $\mu \mathrm{mol} / \mathrm{L}$ ) DE METALES EN EL MATERIAL SUSPENDIDO DE LAS AGUAS DE LA LAGUNA DE UNARE, ESTADO ANZOÁTEGUI, VENEZUELA (REALIZADA EL 25 DE OCTUBRE DE 2002) I TIME SERIES OF METAL CONCENTRATIONS ( $\mu \mathrm{mol} / L$ ) DETERMINED IN SUSPENDED MATERIAL IN THE WATERS OF THE UNARE LAGOON, ANZOÁTEGUI STATE, VENEZUELA (TIME SERIES OBTAINED ON OCTOBER 25, 2002.

concentracion de $\mathrm{Cr}$ oscila entre 0,058-0,077 $\mu \mathrm{mol} / \mathrm{L}$ de $\mathrm{Cr}$ (VI). Los niveles de Cu por otra parte, en aguas naturales están por debajo de $0,39 \mu \mathrm{mol} / \mathrm{L}$ y en las oceánicas en $2 \times 10^{-3}$ $\mu \mathrm{mol} / \mathrm{L}$ [21]. La legislación venezolana establece límites de 1,6 $\times 10^{-3} \mu \mathrm{mol} / \mathrm{L}$ de $\mathrm{Cu}$ para las aguas descargadas al medio marino-costero y valores similares para las aguas de consumo humano, niveles que son inferiores a los determinados en la laguna de Unare. Las concentraciones de hierro a su vez, en agua de mar varían entre 0 y 1,07 $\mu \mathrm{mol} / \mathrm{L}$. La legislación venezolana en la Gaceta Oficial № 34.829 del 29-1-1992, establece valores limites entre $179 \mu \mathrm{mol} / \mathrm{L}$, para las aguas de descargas y $5,36 \mu \mathrm{mol} / \mathrm{L}$ para las aguas destinadas al consumo humano. Estos valores son superiores a los determinados en la presente investigación. 
Cuantificación de las concentraciones de metales pesados en peces de Unare, Anzoátegui, Venezuela / Márquez, A. y col.

El manganeso, en ambientes acuáticos es altamente reactivo y presenta una alta capacidad de adsorción en forma de óxidos coloidales, lo cual contribuye en el comportamiento de otros elementos dentro de los estuarios y lagunas costeras [27]. El níquel a su vez, en agua de mar presenta concentraciones de oscilan desde $1,70 \times 10^{-3}$ a $4,43 \times 10^{-2} \mu \mathrm{mol} / \mathrm{L}$, siendo sus sales tóxicas [18]. La legislación venezolana establece limites de $3,41 \times 10^{-2} \mu \mathrm{mol} / \mathrm{L}$, para aguas a ser descargadas a los medios marinos-costeros, mientras que, no existen lìmites establecidos para las aguas destinadas al consumo humano.Estos valores son superiores a los determinados en el agua de la laguna de Unare.

Las concentraciones de $\mathrm{Pb}$ en aguas oceánicas, están en el orden de $4,8 \times 10^{-6}-1,93 \times 10^{-6} \mu \mathrm{mol} / \mathrm{L}$ [21]. La legislación venezolana establece valores límites de plomo de 2,42 $\mu \mathrm{mol} / \mathrm{L}$ para las aguas de descargas a los medios marino-costero; y niveles de $0,25 \mu \mathrm{mol} / \mathrm{L}$ para las aguas destinadas al consumo humano. Las concentraciones de $\mathrm{Zn}$ a su vez, se encuentra en los océanos en rangos menores a $1,53 \times 10^{-3}$ $\mu \mathrm{mol} / \mathrm{L}$, pero en áreas costeras y estuarios siempre son más altas debido a los aportes de las aguas industriales y urbanas [21]. En las aguas de consumo humano son permitidas concentraciones $3,06 \times 10^{-3} \mu \mathrm{mol} / \mathrm{L}$ [18]. Estos valores son inferiores a los determinados en el agua de la laguna de Unare.

Elbaz-Poulichet y col. [12], sostienen que el agua de los ríos es el principal vehículo de transporte de los elementos metálicos hacia los ambientes lacustres, y que dentro del sistema lagunar la distribución de ellos va a depender de los procesos estuarinos que los controlan; tales como floculación geoquímica, adsorción y desorción de las partículas en suspensión y los procesos biológicos de asimilación, bioturbación, diagénesis, bioacumulación además de otros parámetros y condiciones físico-químicas tales como: $\mathrm{pH}$, temperatura, contenido de oxigeno disuelto, salinidad, fuerza iónica, condiciones redox, mezclado de las aguas y las interacciones de las mismas con los minerales [6].

\section{Metales en sedimentos superficiales}

Uno de los principales problemas al interpretar los resultados e indicar si un sedimento está contaminado en Venezuela, es que se carece de normativas legales que señalen valores considerados como contaminantes para los sedimentos fluviales y marinos, especialmente en la zona costera. En tal sentido, las comparaciones tienen que realizarse mediante valores reportados por autores en zonas que inclusive tienen características geomorfológicas diferentes a las encontradas en el país.

Los porcentajes de extracción de metales en las muestras estudiadas fueron representativos, tal como lo demuestran desviaciones estándar bastante bajas para las réplicas analizadas y la comparación de los promedios obtenidos con el rango aceptable y el valor del patrón certificado (TABLA I). Estos resultados evidencian la calidad analítica de los resultados obtenidos. Las concentraciones determinadas en todos los metales analizados en el sedimento de la laguna de Unare oscilaron en orden decreciente $\mathrm{Mn}(516,37 \mu \mathrm{g} / \mathrm{g})>\mathrm{Zn}(127,49$ $\mu \mathrm{g} / \mathrm{g})>\mathrm{Ni}(52,41 \mu \mathrm{g} / \mathrm{g})>\mathrm{Cr}(51,69 \mu \mathrm{g} / \mathrm{g})>\mathrm{Cu}(41,13 \mu \mathrm{g} / \mathrm{g})>\mathrm{Pb}(29$ $\mu \mathrm{g} / \mathrm{g})>\mathrm{Cd}(1,51 \mu \mathrm{g} / \mathrm{g})$, (TABLA II), sobrepasando en gran magnitud los niveles considerados como contaminantes por Sadiq [37], lo cual pone en evidencia un grave deterioro ecológico en los sedimentos de este importante ecosistema.

El Cd presenta gran afinidad con los halógenos y forma complejos con el cloruro e iones inorgánicos, siendo las actividades antrópicas son consideradas la principal fuente de ingreso a los sistemas acuáticos [37]. Fermin [13] señala concentraciones promedios de $1,51 \mu \mathrm{g} / \mathrm{g}$ de cadmio para los sedimentos de la laguna de Unare indicando que, más de $50 \%$ de las cocentraciones de cadmio en el sedimento de la laguna está asociado a las fracciones biodisponibles (extraidos con acido acetico al $25 \%$ ), mientras que el cromo y cobre están asociados principalmente a la fraccion residual del sedimento (extraidos con mezcla de ácido nítrico y perclórico). El hierro se encuentra entre los metales esenciales para los seres vi-

TABLA /

PRECISIÓN DEL MÉTODO DE EXTRACCIÓN DE METALES PESADOS EN EL SEDIMENTO DE REFERENCIA, PATRÓN Lot. $\mathbf{N}^{\circ}$ 237.Cat. $\mathrm{N}^{\circ} 540$ / PRECISION OF THE EXTRACTION METHODS OF TOTAL HEAVY METALS IN THE REFERENCE SEDIMENT, Lot $\mathrm{N}^{\circ} 237$, Cat. $\mathrm{N}^{\circ} 540$.

\begin{tabular}{ccccc}
\hline Metal & Valor Experimental $(\mu \mathrm{g} / \mathrm{g})$ & Valor Certificado $(\mu \mathrm{g} / \mathrm{g})$ & Rango Aceptable $(\mu \mathrm{g} / \mathrm{g})$ & DS \\
\hline $\mathrm{Cd}$ & 48,11 & 52,40 & $40,30-64,50$ & 0,51 \\
$\mathrm{Cr}$ & 81,34 & 88,20 & $70,50-106$ & 0,44 \\
$\mathrm{Cu}$ & 107,01 & 108,00 & $88,70-127$ & 0,58 \\
$\mathrm{Fe}$ & 7990,82 & 7760 & $2890-12600$ & 5,78 \\
$\mathrm{Ni}$ & 51,67 & 55,90 & $43,70-68$ & 0,44 \\
$\mathrm{Mn}$ & 111,65 & 127 & $101-154$ & 1,16 \\
$\mathrm{~Pb}$ & 70,608 & 75,10 & $57,2-93$ & 1,22 \\
$\mathrm{Zn}$ & 87,57 & 87,80 & $67,9-108$ & 0,44 \\
\hline
\end{tabular}

DS= Desviación estándar. 
TABLA /I
COMPARACIÓN DE LAS CONCENTRACIONES ( $\mu \mathrm{g} / \mathrm{g})$ DE METALES EN SEDIMENTOS DE LA LAGUNA DE UNARE, ESTADO ANZOÁTEGUI VENEZUELA Y LOS REPORTADOS POR SADIQ (1992) PARA SEDIMENTOS NO CONTAMINADOS I METAL CONCENTRATIONS $(\mu \mathrm{g} / \mathrm{g})$ FOR SEDIMENTS OF THE UNARE LAGOON, ANZOÁTEGUI STATE, VENEZUELA, COMPARED WITH THOSE REPORTED BY SADIQ (1992) FOR UNPOLLUTED SEDIMENTS.

\begin{tabular}{|c|c|c|c|c|c|c|c|}
\hline & $\mathrm{Cd}(\mu \mathrm{g} / \mathrm{g})$ & $\mathrm{Cr}(\mu \mathrm{g} / \mathrm{g})$ & $\mathrm{Cu}(\mu \mathrm{g} / \mathrm{g})$ & $\mathrm{Mn}(\mu \mathrm{g} / \mathrm{g})$ & $\mathrm{Ni}(\mu \mathrm{g} / \mathrm{g})$ & $\mathrm{Pb}(\mu \mathrm{g} / \mathrm{g})$ & $\mathrm{Zn}(\mu \mathrm{g} / \mathrm{g})$ \\
\hline Min & 0,46 & 19,45 & 20,50 & 276,80 & 22,02 & 10,80 & 83,08 \\
\hline Max & 2,68 & 85,85 & 55,59 & 971,0 & 70,88 & 43,80 & 334,48 \\
\hline Prom & 1,51 & 51,69 & 41,13 & 516,37 & 52,41 & 29,00 & 127,49 \\
\hline $\begin{array}{l}\text { Sedimento no contaminado } \\
\text { (Sadiq, 1992) }\end{array}$ & $<1$ & $<20$ & $<10$ & - & $<10$ & $<5$ & $<110$ \\
\hline
\end{tabular}

Min = Valor mínimo. Max = valor máximo. Prom = Promedio.

vos, debido a que intervienen en una gran variedad de funciones biológicas y bioquímicas [1, 25], sin embargo, es tóxico cuando se encuentra en altas concentraciones. En otros ecosistemas venezolanos, se han señalado promedios de hierro de 1,61\%; para los sedimentos de la cuenca Tuy-Cariaco [16], de 1,48\%; para los sedimentos superficiales de la laguna de Las Marites [38], y 5,2\% en la bahía de Barcelona [17]. Igualmente, valores de $1,56 \%$ de hierro han sido indicados para la laguna de Unare, observándose que el hierro se encuentra en mayor proporción como forma de hierro residual [13]. En la laguna Píritu por su parte, los sedimentos presentan niveles de hierro cercanos a $2,66 \%$, de los cuales la mayor proporción se encuentra principalmente asociado a las fracciones materia orgánica y a los óxidos de hierro y manganeso [22].

En los sistemas acuáticos, el manganeso presenta una gran reactividad, especialmente en sistemas estuarinos, y la alta capacidad de adsorción de metales, contribuyendo significativamente a la caracterización y el comportamiento de estos elementos en los estuarios y lagunas [31]. Para la bahía de Pozuelos en el estado Anzoátegui y áreas adyacentes, se han reportado niveles manganeso entre $8 \mu \mathrm{g} / \mathrm{g}$ y $70 \mu \mathrm{g} / \mathrm{g}$ [19]. Para los sedimentos de la laguna de Chacopata, valores de 24,84 $\mu \mathrm{g} / \mathrm{g}$ han sido señalados [14]. Para laguna de Píritu y Unare se han indicado concentraciones de manganeso entre 47,12 $\mu \mathrm{g} / \mathrm{g}$ y $1685,50 \mu \mathrm{g} / \mathrm{g}$ y entre $276,80 \mu \mathrm{g} / \mathrm{g}-971 \mu \mathrm{g} / \mathrm{g}$, respectivamente $[16,22]$. Los valores de niquel se han incrementado en la laguna de Unare con el pasar del tiempo. Senior y col. [41] reportaron valores promedios de niquel de $33,86 \mu \mathrm{g} / \mathrm{g}$ para la laguna de Unare, concentraciones que son inferiores a las determinados en esta investigación. Por otra parte, se han señalado promedios de plomo que alcanzan $11,70 \mu \mathrm{g} / \mathrm{g}$ en los sedimentos superficiales de la bahía de Pozuelos [40], y 8,66 $\mu \mathrm{g} / \mathrm{g}$ para los de la laguna de Chacopata [19]. Igualmente valores de $29 \mu \mathrm{g} / \mathrm{g}$ y $16,50 \mu \mathrm{g} / \mathrm{g}$ para las lagunas de Unare y Píritu, respectivamente, en el estado Anzoátegui [17, 22].

El zinc es un metal que es requerido por el organismo, sin embargo, un aumento en las concentraciones lo hace tóxico para los organismos acuáticos. En la cuenca Tuy-Cariaco, se han determinado promedios de $57,18 \mu \mathrm{g} / \mathrm{g}$ en los sedimen- tos superficiales [16]. Medias de $300 \mu \mathrm{g} / \mathrm{g}$ de $\mathrm{Zn}$ han sido reportadas en los sedimentos superficiales de la bahía de Pozuelos [40], indicándose en este último caso, existencia de contaminación por zinc, mientras que concentraciones promedios de $127,49 \mu \mathrm{g} / \mathrm{g}$ y $116,69 \mu \mathrm{g} / \mathrm{g}$, también han sido señaladas para las lagunas de Unare y Píritu, respectivamente [17, 22].

\section{Metales en organismos}

La tasa de recuperación de las medidas del material de referencia para el tejido de los organismos (TABLA III) fue confiable y estuvo dentro de un límite de confianza de $95 \%$ del valor publicado para este material. Por otra parte, resultados mostraron diferencias significativas $(P<0,05)$ en las concentraciones de todos los metales para las diferentes especies (TABLA IV).

Las concentraciones de cadmio (TABLA V) en todas las especies fueron inferiores a $0,88 \mu \mathrm{g} / \mathrm{g}$, observándose el máximo valor en $E$. Saurus y el menor en $M$. curema $(0,04 \mu \mathrm{g} / \mathrm{g})$. Niveles intermedios entre $0,052 \mu \mathrm{g} / \mathrm{g}$ y $0,094 \mu \mathrm{g} / \mathrm{g}$ fueron determinados para el resto de las especies. Los valores de $\mathrm{Cr}$ fueron mayores en $C$. spixii y $M$. garmaidianus, donde se detectaron niveles de $0,30 \mu \mathrm{g} / \mathrm{g}$ y $0,26 \mu \mathrm{g} / \mathrm{g}$; por su parte $E$. saurus al igual que $P$. schmitti presentaron valores muy similares que alcanzan los $0,13 \mu \mathrm{g} / \mathrm{g}$ y $0,15 \mu \mathrm{g} / \mathrm{g}$, respectivamente. $\mathrm{Ni}-$ veles de 0,07 fueron apreciados para $M$. curema y $M$. liza, no detectándose este metal en la especie $C$. undecimalis. Los niveles de cobre a su vez, oscilaron entre $9,86 \mu \mathrm{g} / \mathrm{g}$ en $P$. schmitti y $0,62 \mu \mathrm{g} / \mathrm{g}$ en $C$. undecimalis. Igualmente valores de $2,83 \mu \mathrm{g} / \mathrm{g}$ fueron observados en $M$. garmaidianus y valores entre $0,81-1,72 \mu \mathrm{g} / \mathrm{g}$ se detectaron en las especies $E$. saurus y M. liza.

Las concentraciones promedios de hierro variaron desde $7,76 \mu \mathrm{g} / \mathrm{g}$ en Mugil Curema hasta un máximo de $30,27 \mu \mathrm{g} / \mathrm{g}$ en Centropomus undecimalis, encontrándose valores intermedios

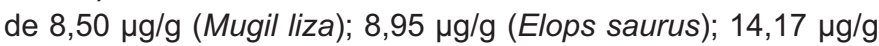
(Mugil garmaidianus) y niveles de $19,04 \mu \mathrm{g} / \mathrm{g}$ en el crustáceo $P$. schmitti. Los niveles de hierro determinadas en esta investigación son inferiores a los reportados por Biddiger y Gloss para los tejidos musculares de otras especies como T. nilotica, 
Cuantificación de las concentraciones de metales pesados en peces de Unare, Anzoátegui, Venezuela / Márquez, A. y col.

C. mrigala y $C$. batrachus, para las cuales se han señalado valores de $131 \mu \mathrm{g} / \mathrm{g}$ [3]. Igualmente a los valores reportados para Lisa Dumerelli [26].

Las concentraciones de manganeso, oscilaron entre 2,93 $\mu \mathrm{g} / \mathrm{g}$ y $0,56 \mu \mathrm{g} / \mathrm{g}$ en $P$. schmitti y $M$. liza, respectivamente, con promedios entre $0,58 \mu \mathrm{g} / \mathrm{g}$ y $2,11 \mu \mathrm{g} / \mathrm{g}$ para el resto de las especies. Los valores de cobre determinados estuvieron comprendidos entre $9,86 \mu \mathrm{g} / \mathrm{g}$ en $P$. schmitti y $0,62 \mu \mathrm{g} / \mathrm{g}$ en $C$. undecimalis. Igualmente, niveles de $2,83 \mu \mathrm{g} / \mathrm{g}$ fueron observados en $M$. garmaidianus y concentraciones entre 0,81-1,72 $\mu \mathrm{g} / \mathrm{g}$ se detectaron en las especies E. saurus y $M$. liza. Para níquel, los valores fueron máximos en Centropomus undecimalis $(1,94 \mu \mathrm{g} / \mathrm{g})$ con niveles de $0,87 \mu \mathrm{g} / \mathrm{g}$ y $0,81 \mu \mathrm{g} / \mathrm{g}$ en $C$. spixii y $E$. saurus y
TABLA III

CONCENTRACIONES DE METALES MEDIDAS EN EL MATERIAL DE REFERENCIA DE TEJIDOS DE Mytilus edulis / METAL CONCENTRATIONS MEASURED IN THE REFERENCE MATERIAL OF TISSUES OF Mytilus edulis

\begin{tabular}{ccc}
\hline Metal $(\mu \mathrm{g} / \mathrm{g})$ & $\begin{array}{c}\text { Medidas } \\
\text { del BCR 278 }\end{array}$ & \multicolumn{1}{c}{$\begin{array}{c}\text { Valores } \\
\text { certificados del BCR }\end{array}$} \\
\hline $\mathrm{Cr}$ & $0,78 \pm 0,06$ & $0,80 \pm 0,73$ \\
$\mathrm{Cu}$ & $9,45 \pm 0,13$ & $9,37 \pm 0,18$ \\
$\mathrm{Mn}$ & $7,69 \pm 0,23$ & $7,60 \pm 0,20$ \\
$\mathrm{~Pb}$ & $2,00 \pm 0,04$ & $1,99 \pm 0,19$ \\
$\mathrm{Zn}$ & $83,10 \pm 1,70$ & $81,20 \pm 1,82$ \\
\hline
\end{tabular}

TABLA IV

COMPARACIÓN (STUDENT-NEWMAN-KEULS) DE LAS CONCENTRACIONES DE METALES $(P<0,05)$ EN TEJIDOS MUSCULARES DE PECES Y CAMARONES DE LA LAGUNA DE UNARE, ESTADO ANZOÁTEGUI VENEZUELA / COMPARISON (STUDENT-NEWMAN-KEULS) OF THE METAL CONCENTRATIONS $(P<0.05)$ IN THE MUSCULAR TISSUES OF FISH AND SHRIMP FROM THE UNARE LAGOON, ANZOÁTEGUI STATE, VENEZUELA

\begin{tabular}{|c|c|c|c|c|c|}
\hline \multicolumn{3}{|c|}{$\mathrm{Cd}$} & \multicolumn{3}{|c|}{$\mathrm{Cr}$} \\
\hline Especie & Prom & Grupos & Especie & Prom & Grupos \\
\hline Mugil curema & 0,04 & $x$ & Centropomus undecimalis & ND & $\mathrm{X}$ \\
\hline Mugil liza & 0,052 & $x$ & Mugil curema & 0,07 & $x X$ \\
\hline Mugil gaimardianus & 0,056 & $x$ & Mugil liza & 0,07 & $X X$ \\
\hline P. schmitti & 0,065 & $x$ & P. schmitti & 0,13 & $x$ \\
\hline Centropomus undecimalis & 0,072 & $x$ & Elops saurus & 0,15 & $X$ \\
\hline Elops saurus & 0,88 & $x$ & Mugil gaimardianus & 0,26 & $x$ \\
\hline Cathorops spixi & 0,09 & $\mathrm{X}$ & Cathorops spixi & 0,08 & $\mathrm{X}$ \\
\hline \multicolumn{3}{|c|}{$\mathrm{Cu}$} & \multicolumn{3}{|c|}{$\mathrm{Fe}$} \\
\hline Especie & Prom & Grupos & Especie & Prom & Grupos \\
\hline Centropomus undecimalis & 0,62 & $\mathrm{x}$ & Mugil curema & 7,76 & $x$ \\
\hline Elops saurus & 1,07 & $X X$ & Mugil liza & 8,50 & $x X$ \\
\hline Mugil liza & 1,30 & $X X$ & Elops saurus & 8,95 & $X X$ \\
\hline Mugil curema & 1,58 & $x X$ & Mugil gaimardianus & 14,17 & $x X$ \\
\hline Cathorops spixi & 0,08 & $X X$ & Cathorops spixi & 2,68 & $X X$ \\
\hline Mugil gaimardianus & 2,83 & $\mathrm{X}$ & P. schmitti & 19,04 & $x$ \\
\hline P. schmitti & 9,86 & $x$ & Centropomus undecimalis & 30,27 & $x$ \\
\hline \multicolumn{3}{|c|}{$\mathrm{Mn}$} & \multicolumn{3}{|c|}{$\mathrm{Ni}$} \\
\hline Especie & Prom & Grupos & Especie & Prom & Grupos \\
\hline Mugil liza & 0,56 & $x$ & Mugil curema & ND & $x$ \\
\hline Centropomus undecimalis & 0,58 & $X$ & Mugil liza & ND & $x$ \\
\hline Elops saurus & 0,81 & $X X$ & Mugil gaimardianus & 0,27 & $X$ \\
\hline Mugil curema & 1,21 & $\mathrm{X}$ & P. schmitti & 0,44 & $x$ \\
\hline Mugil gaimardianus & 1,72 & $x$ & Elops saurus & 0,81 & $x$ \\
\hline Cathorops spixi & 1,49 & $x$ & Cathorops spixi & 0,14 & $\mathrm{X}$ \\
\hline P. schmitti & 2,93 & $x$ & Centropomus undecimalis & 1,94 & $x$ \\
\hline \multicolumn{3}{|c|}{$\mathrm{Pb}$} & \multicolumn{3}{|c|}{$\mathrm{Zn}$} \\
\hline Especie & Prom & Grupos & Especie & Prom & Grupos \\
\hline Centropomus undecimalis & ND & $x$ & Centropomus undecimalis & 8,71 & $x$ \\
\hline Mugil gaimardianus & 0,12 & $\mathrm{X}$ & Elops saurus & 18,81 & $\mathrm{X}$ \\
\hline Cathorops spixi & 0,22 & $X$ & Mugil gaimardianus & 17,29 & $x$ \\
\hline Elops saurus & 0,16 & $X X$ & Cathorops spixi & 22,51 & $X$ \\
\hline Mugil liza & 0,22 & $x X$ & Mugil curema & 20,39 & $x X$ \\
\hline P. Schmitti & 0,26 & $X$ & Mugil liza & 23,50 & $\mathrm{X}$ \\
\hline Mugil curema & 0,28 & $\mathrm{X}$ & P. schmitti & 25,04 & $\mathrm{X}$ \\
\hline
\end{tabular}


TABLA V

CONCENTRACIONES PROMEDIOS DE METALES $(\mu \mathrm{g} / \mathrm{g})$ Y VALORES DEL PARÁMETRO $F(P<0,05)$ OBTENIDOS DE LA PRUEBA ESTADÍSTICA DE ANOVA APLICADA EN TEJIDOS MUSCULARES DE PECES Y CAMARONES DE LA LAGUNA DE UNARE, ESTADO ANZOÁTEGUI VENEZUELA / MEAN CONCENTRATIONS OF METALS ( $\mu \mathrm{g} / \mathrm{g}$ ) AND VALUE OF THE $F$ PARAMETER $(P<0.05)$ OBTAINED FROM THE ANOVA STATISTICAL TEST FOR MUSCULAR TISSUES OF FISH AND SHRIMP FROM THE UNARE LAGOON, ANZOÁTEGUI STATE, VENEZUELA

\begin{tabular}{lccccccccccc}
\hline \multicolumn{1}{c}{ Especie } & $\mathrm{T}(\mathrm{cm})$ & $\mathrm{N}$ & $\mathrm{Cd}$ & $\mathrm{Cr}$ & $\mathrm{Cu}$ & $\mathrm{Fe}$ & $\mathrm{Mn}$ & $\mathrm{Ni}$ & $\mathrm{Pb}$ & $\mathrm{Zn}$ \\
\hline $\begin{array}{l}\text { Cathorops spixii } \\
\text { (interior de la laguna) }\end{array}$ & 32 & 23 & $0,09 \pm 0,001$ & $0,08 \pm 0,02$ & $2,68 \pm 0,24$ & $21,76 \pm 1,35$ & $1,49 \pm 0,09$ & $0,14 \pm 0,06$ & $0,22 \pm 0,02$ & $22,51 \pm 0,10$ \\
$\begin{array}{l}\text { Cathorops spixii } \\
\text { (fuera de la laguna) }\end{array}$ & 32 & 19 & $0,08 \pm 0,02$ & $0,58 \pm 0,02$ & $1,4 \pm 0,20$ & $6,86 \pm 1,30$ & $1,10 \pm 0,09$ & $0,18 \pm 0,05$ & $\mathrm{ND}$ & $14,98 \pm 0,10$ \\
$\begin{array}{l}\text { Centropomus } \\
\text { undecimalis }\end{array}$ & 23 & 32 & $0,072 \pm 0,002$ & $\mathrm{ND}$ & $0,62 \pm 0,06$ & $30,27 \pm 1,89$ & $0,58 \pm 0,15$ & $1,94 \pm 0,09$ & $\mathrm{ND}$ & $8,71 \pm 1,64$ \\
$\begin{array}{l}\text { Elops saurus } \\
\text { Mugil curema }\end{array}$ & 20 & 36 & $0,88 \pm 0,001$ & $0,15 \pm 0,02$ & $1,07 \pm 0,39$ & $8,95 \pm 1,26$ & $0,81 \pm 0,10$ & $0,81 \pm 0,06$ & $0,16 \pm 0,03$ & $18,81 \pm 1,09$ \\
$\begin{array}{l}\text { Mugil gaimardianus } \\
\text { Mugil liza }\end{array}$ & 16 & 47 & $0,056 \pm 0,001$ & $0,26 \pm 0,02$ & $2,83 \pm 0,35$ & $14,17 \pm 1,10$ & $1,72 \pm 0,09$ & $0,27 \pm 0,05$ & $0,12 \pm 0,02$ & $17,29 \pm 0,95$ \\
P. schmitti & 43 & 26 & $0,052 \pm 0,001$ & $0,07 \pm 0,03$ & $1,30 \pm 0,47$ & $8,50 \pm 1,48$ & $0,56 \pm 0,12$ & $\mathrm{ND}$ & $0,22 \pm 0,03$ & $23,50 \pm 1,28$ \\
\hline
\end{tabular}

$\mathrm{T}=$ Talla promedio $(\mathrm{cm}) . N=$ tamaño de la muestra.

$0,27 \mu \mathrm{g} / \mathrm{g}$ y $0,44 \mu \mathrm{g} / \mathrm{g}$ para $M$. garmaidianus y $P$. schmitti, respectivamente. Sin embargo, en E. saurus y M. liza no fue detectado este elemento. El plomo no se detectó en la especie C. undecimales, sin embargo, valores entre $0,12 \mu \mathrm{g} / \mathrm{g} \mathrm{y}$ $0,16 \mu \mathrm{g} / \mathrm{g}$ fueron cuantificados en $M$. garmaidianus, C. spixii y E. saurus. De igual manera, los máximos valores para este elemento fueron observados en las especies $M$. liza, $M$. curema y en el crustáceo $P$. schmitt, $i$ donde los niveles fueron superiores a $0,20 \mu \mathrm{g} / \mathrm{g}$. Estos niveles son inferiores a los reportados para otras especies como Diaplerus plumeri [35]. Los valores de $\mathrm{Zn}$, fueron altos, inclusive mayores que los de hierro, con niveles que superaron los $8,71 \mu \mathrm{g} / \mathrm{g}$ (C. undecimales). Se determinaron valores entre $16,81 \mu \mathrm{g} / \mathrm{g}$ y $17,80 \mu \mathrm{g} / \mathrm{g}$ para $E$. saurus, $M$. garmaidianus y C. spixii y concentraciones entre 20 $\mu \mathrm{g} / \mathrm{g}$ y $23 \mu \mathrm{g} / \mathrm{g}$ para $M$. curema, $M$. liza, correspondiendo el valor máximo de 25,04 $\mu \mathrm{g} / \mathrm{g}$ para el crustáceo $P$. schmitti.

Los peces concentran metales en el cuerpo en proporciones variables, que dependen de la especie, condiciones medio ambientales y los procesos inhibitorios. Subsecuentemente, estos organismos constituyen una fuente importante de alimento para los humanos, por lo que se establecen como una fuente potencial indirecta de metales que entra al organismo. Estos elementos a la vez generan una serie de efectos metabólicos, fisiológicos, conductuales y ecológicos [42, 46, 47]. En esta investigación se observó que existen discrepancias en la concentracion de cada metal presente en el tejido de cada especie evaluada (TABLA IV), observándose a la vez diferencias en las concentraciones presentes en organismos de la misma especie que habitan dentro y fuera de la laguna.Un ejemplo lo constituyen los individuos de C. spixii,a los que se les determinó un mayor contenido de metales (con excepción de níquel y cromo) en los ejemplares que habitan dentro de la laguna (TABLA VI). Esto pone en evidencia una probable bioa- cumulación de los metales debido al mayor tiempo de retención de las aguas dentro de la laguna y al impacto ecológico existente en los sedimentos. Arias y col. [2] indican, que las diferencias entre las concentraciones de metales presentes en los ejemplares de una misma familia pudieran ser discutidas en base a la posibilidad de efectos genotípicos en la misma especie y su relación con la contaminación de la laguna, además de los efectos nocivos sobre la salud humana a través de la cadena alimenticia.

Los resultados obtenidos en esta investigación reflejan quizás, dos posibles procesos que contribuyen a la forma como es asimilado el metal por cada una de las especies. En primer lugar, el tipo de alimentación y en segundo, una progresiva bioacumulación, ya sea a partir de la absorción del metal desde el agua o desde el sedimento, aunque desde este último pareciera ser un mecanismo más factible, se toma en consideración los altos niveles presentes (TABLA II). Aunque la concentración de todos los metales evaluados en el agua se encuentran en baja concentración durante las 24 horas del día (FIG. 2), no es descartable la bioacumulación a partir del agua, puesto que la asimilación de bajas concentraciones en períodos de tiempos prolongados inducen estos mecanismos en los organismos.

Los hábitos ecológicos de las diferentes especies, afectan en gran forma la captación del metal por el pez. Por ejemplo, E. saurus es una especie eurialina que se encuentra principalmente en fondos blandos en la plataforma continental en aguas neriticas hasta $50 \mathrm{~m}$ de profundidad. C. spixii vive en fondos fangosos en las lagunas litorales y estuarios de la costa venezolana, $M$. garmaidianus, $M$. Curema y $M$. liza son detrívoras que viven en los fondos someros de la plataforma continental y lagunas litorales [25]. En cuanto a los crustáceos, estudios sobre los hábitos alimenticios han demostrado que los 
TABLA VI

CONCENTRACIONES DE METALES PESADOS $(\mu \mathrm{g} / \mathrm{g})$ Y VALOR $F(N=41 ; P<0,05)$ SEGÚN LA PRUEBA ESTADÍSTICA DE ANOVA EN Cathorops spixii DE LAGUNA DE UNARE Y DE LA ZONA MARINA EN EL ESTADO ANZOÁTEGUI, VENEZUELA / HEAVY METAL CONCENTRATIONS $(\mu \mathrm{g} / \mathrm{g})$ AND VALUE OF THE $F$ PARAMETER $(\mathrm{N}=41, P<0.05)$ OBTAINED FROM THE ANOVA STATISTICAL TEST FOR Cathorops spixii FROM THE UNARE LAGOON AND FROM THE MARINE ZONE OF THE ANZOÁTEGUI STATE, VENEZUELA.

\begin{tabular}{|c|c|c|c|c|c|}
\hline Metales $(\mu \mathrm{g} / \mathrm{g})$ & $\begin{array}{l}\text { Cathorops spixii } \\
\text { (Laguna Unare) }\end{array}$ & $\begin{array}{c}\text { Cathorops spixii } \\
\text { (Mar) }\end{array}$ & $\mathrm{N}$ & $\mathrm{F}$ & NS \\
\hline $\mathrm{Cd}$ & $0,09 \pm 0,001$ & $0,08 \pm 0,02$ & & 1,97 & * \\
\hline $\mathrm{Cr}$ & $0,08 \pm 0,02$ & $0,58 \pm 0,02$ & & 1,97 & * \\
\hline $\mathrm{Cu}$ & $2,68 \pm 0,24$ & $1,4 \pm 0,20$ & & 1,21 & * \\
\hline $\mathrm{Fe}$ & $21,76 \pm 1,35$ & $6,86 \pm 1,30$ & & 8,57 & * \\
\hline $\mathrm{Mn}$ & $1,49 \pm 0,09$ & $1,10 \pm 0,09$ & & 2,86 & * \\
\hline $\mathrm{Ni}$ & $0,14 \pm 0,06$ & $0,18 \pm 0,05$ & & & \\
\hline $\mathrm{Pb}$ & $0,22 \pm 0,02$ & ND & & - & * \\
\hline $\mathrm{Zn}$ & $22,51 \pm 0,10$ & $14,98 \pm 0,10$ & & 1,47 & * \\
\hline $\mathrm{n}$ & 23 & 19 & 41 & & \\
\hline
\end{tabular}

NS= nivel de significancia. $\quad$ *=significativo. $\quad \mathrm{ND}=$ no detectado. $\mathrm{n}=$ número de organismos.

camarones peneidos son omnívoros, y que algunas especies presentan tendencias hacia la carnivoría o a la herbivoría, sin embargo, $P$. schmitti tiene hábitos omnívoro-herbívoros [39]. Todas las especies que se alimentan del fango fueron las que presentan los mayores niveles de metales en la laguna de Unare. Por otra parte, C. undecimalis que es una especie carnívora y que se alimenta especialmente de camarones y peces, pareciera no estar asimilando el metal desde su alimento, ya que en sus tejidos solo las concentraciones de hierro y níquel son ligeramente superiores a los niveles encontrados en el resto de las especies evaluadas.

Algunos de estos niveles de metales detectados como cobre y cadmio, no parecieran evidenciar riesgo por el momento para algunas especies como $M$. curema, que es un habitante común de la laguna de Unare y que ha sido comprobado que concentraciones de aproximadamente $2,33 \mu \mathrm{g} / \mathrm{g}$ de cobre pueden causar la muerte en tan solo 96 horas de exposición a temperatura ambiente [5]. Sin embargo, este no sería el caso para los crustáceos ya que mediante estudios de determinado que en algunos crustáceos, específicamente las larvas nauplii de el camarón comercial Artemesia longinaris existe una relación directa entre mortalidad y concentración de cobre y señala que a concentraciones de $1 \mu \mathrm{g} / \mathrm{mL}$ de $\mathrm{Cu}$, los nauplii mueren en menos de 24 h [39]. Diversos experimentos de toxicidad han demostrado que los organismos acuáticos son más sensibles al cobre que a otros iones de metales pesados [34]. En las algas, camarones, cangrejos, moluscos bivalvos y peces, la biodisponibilidad y toxicidad del cobre puede ser reducida tanto por la presencia de iones inorgánicos como por los quelantes orgánicos hallados en aguas naturales que forman complejos con el cobre o quelantes inorgánicos agregados al agua [45].

Al igual que ocurre para el cobre sucede para el cadmio, en el cual se ha determinado una dosis letal media de $10 \mu \mathrm{g} / \mathrm{g}$ de Cd para M. curema, a temperatura ambiente en $96 \mathrm{~h}$ [5]. Explica el autor que niveles subletales (a partir de $3 \mu \mathrm{g} / \mathrm{g}$ ) producen modificaciones en las células branquiales, afectando las funciones respiratorias. Estas concentraciones reportadas por Boada [5], son superiores a las determinadas en esta investigación. Untersteiner y col. [46] indican que, la exposición al cadmio en el orden de $1 \mathrm{mg} / \mathrm{l}$ en un tiempo menor de $12 \mathrm{~h}$ produce cambios drásticos en el sistema de locomoción del camarón Hippolyte inermis. Para el zinc, el caso es diferente a lo que se conoce para el cobre y cadmio, el valor letal medio señalado por Arias y col. [2] es $6,15 \mu \mathrm{g} / \mathrm{g}$ para la $M$. curema, a temperatura ambiente y durante 96 horas de exposición. Las concentraciones de zinc determinadas en este estudio, en los tejidos de las diferentes especies, exceptuando $C$. undecimalis $(8,71 \mu \mathrm{g} / \mathrm{g})$, triplican estos valores poniendo de manifiesto un potencial peligro para las especies que habitan dentro de la laguna.

En el sedimento de la laguna de Unare (TABLA II) los valores en el $\mathrm{Zn}$ son elevados $(217,49 \mu \mathrm{g} / \mathrm{g})$. Estos niveles son superiores al valor de $110 \mu \mathrm{g} / \mathrm{g}$ que son considerados para sedimentos no contaminados [37]. Esta última observación pareciera confirmar la existencia de una asimilación del $\mathrm{Zn}$ desde el sedimento. En especies de Mugil cephalus, han reportado bioacumulación de zinc [32]. El zinc es un elemento nutritivo para los organismos, sin embargo, altas concentraciones en los peces influyen negativamente en el sistema de reproducción, causando problemas en las branqueas, generando estrés, abrasión de la piel, hemorragia en las aletas y degeneración de la actividad hepática [11, 20, 21].

En el ambiente acuático, el zinc se asocia principalmente con materia en suspensión antes de acumularse finalmente en el sedimento [37]. Las evidencias sobre la biodisponibilidad del zinc en sedimentos han sido documentadas en investiga- 
ciones de plantas e invertebrados que se alimentan de los sedimentos, tal es el caso de los moluscos y algas recogidos en el río Ebro, las cuales reflejan las concentraciones de este metal en los sedimentos [43]. Otros investigadores han indicado que los organismos relacionados con el sedimento presentan concentraciones de zinc más elevadas que los organismos que habitan en la capa acuosa [4]. En el río La Plata (Argentina) se determinó bioacumulación de zinc en peces y organismos bentónicos relacionados con los sedimentos contaminados, apreciándose niveles desde 80 a $109 \mu \mathrm{g} / \mathrm{g}$ en peces y de 340 a $450 \mu \mathrm{g} / \mathrm{g}$ en los tejidos pancreáticos de los caracoles [48].

Especies como las lisas utilizan tres diferentes vías para captar el metal que está asociado al sedimento: Absorción por las agallas y por el tracto digestivo de finas partículas que son resuspendidas en la columna de agua, lixiviado de los contaminantes sedimentarios del agua los cuales son acumulados en el cuerpo del pez vía respiración y contacto directo a través de la piel almacenandose finalmente en los tejidos musculares [9]. La resistencia de organismos acuáticos a los contaminantes, como los metales pesados es motivada por la aclimatación fisiológica o adaptación evolutiva. Un número extenso de estudios llevado en los laboratorios con diferentes especies marinas han mostrado cómo la absorción de metales pesados afecta ciertos genotipos, alterando consecuentemente los diferentes genes [10]. Esta alteración ha producido una reducción de diversidad genética que podría llevar potencialmente a la inestabilidad de la población, incrementando el riesgo de desaparición de poblaciones en los ecosistemas [36].

En los crustáceos, la asimilación de metales como cadmio y zinc, puede ser siempre explicada en términos más allá de los cambios fisicoquímicos. Asi, la bioacumulación se incrementa con el aumento de los niveles de las especies disueltos en el agua como los iones libres hidratados, los cuales a su vez son afectados por los cambios de salinidad y por la presencia de agentes quelantes. Metales como $\mathrm{Cd}, \mathrm{Cu}, \mathrm{Cr}, \mathrm{Zn}$ y $\mathrm{Pb}$, y en especial el plomo, producen la disminución de los hemocitos del camarón Palaemon elegans [23]. En la TABLA VII, se presenta una comparación de los niveles de metales determinados en los tejidos musculares en algunas especies de ecosistemas y las estudiadas en la laguna de Unare durante la presente investigación, notándose una gran heterogeneidad en los niveles de los diferentes metales para cada especie y para cada ecosistema.

La laguna de Unare ha sido centro de interés desde más de 30 años. Estudios recientes han confirmado la existencia de un deterioro en los sedimentos del ecosistema, específicamente en los sedimentos [19], ésto es corroborado con los niveles encontrados en el sedimento en la presente investigación. Por otra parte, esta intervención ha afectado la producción en la laguna de especies como el lebranche $(M$. liza) según lo reportado por Guerra y Marín [19] quienes indican que ésta alcanzó 542 toneladas métricas en 1992 disminuyendo hasta 33 toneladas métricas en 1996. Los resultados muestran

TABLA VII

COMPARACIÓN DE LOS VALORES DE METALEs $(\mu \mathrm{g} / \mathrm{g})$ REPORTADOS PARA ALGUNOS PECES Y CRUSTÁCEOS A NIVEL MUNDIAL Y LOS DETECTADOS EN LAS ESPECIES DE LA LAGUNA DE UNARE, ESTADO ANZOÁTEGUI VENEZUELA (ND = NO DETECTADO) / METAL CONCENTRATIONS $(\mu \mathrm{g} / \mathrm{g})$ REPORTED FOR SOME FISH AND CRUSTACEANS WORLD WIDE AND THOSE DETECTED IN THE SPECIES FROM THE UNARE LAGOON, ANZOÁTEGUI STATE, VENEZUELA. (ND = NOT DETECTED)

\begin{tabular}{|c|c|c|c|c|c|c|c|c|c|}
\hline Especie & $\mathrm{Cd}$ & $\mathrm{Cr}$ & $\mathrm{Cu}$ & $\mathrm{Fe}$ & $\mathrm{Mn}$ & $\mathrm{Ni}$ & $\mathrm{Pb}$ & $\mathrm{Zn}$ & Referencia \\
\hline Lisa dumerelli & - & $2,5-87,5$ & $0,5-24,3$ & $70-1471$ & - & - & $0,41-50,5$ & $33,7-894$ & [29] \\
\hline Ribbed mussels & $2,3-8,5$ & $0,56-9,5$ & $12-66$ & $116-680$ & - & $0,31-1,42$ & - & $11-85$ & [33] \\
\hline Liza aurata & $0,013-0,03$ & $0,029-0,038$ & $0,2-0,6$ & $4,11-7,13$ & $2,25-2,50$ & $0,021-0,70$ & - & & {$[50]$} \\
\hline Anguilla anguilla & $0,015-0,050$ & $0,143-0,364$ & $0,5-1,5$ & $4,11-5,89$ & $4,71-14,1$ & $0,016-0,020$ & $0,03-0,09$ & $10,1-13$ & {$[50]$} \\
\hline Solen vulgaris & $0,01-0,028$ & $0,033-0,045$ & $0,4-0,5$ & $2,13-5,01$ & $1,27-7,16$ & $0,022-0,067$ & $0,03-0,05$ & $4,17-8,52$ & {$[50]$} \\
\hline Diaplerus plumieri & $0,01-0,46$ & - & $0,39-4,94$ & - & - & - & $0,008-0,47$ & $21,2-36,3$ & {$[56]$} \\
\hline Englis sole & $0,07-5$ & ND-0,97 & $1,2-46$ & - & - & $0,29-25$ & ND-1,8 & & [7] \\
\hline Penaeaus monodon & $0,2-0,3$ & $1,7-2,9$ & $12,2-21,3$ & $9,1-15,7$ & $3,1-6,5$ & $2,9-5,9$ & $0,8-1,3$ & $24,2-35,7$ & {$[45]$} \\
\hline Sanilurus polyphagus & $0,3-0,4$ & $3,1-2,5$ & $25,8-35,7$ & $21,4-35,6$ & $4,1-10,1$ & $3,1-7,0$ & $1-1,9$ & $17,6-64,5$ & [45] \\
\hline Cathorops spixii & $0,043-0,11$ & $0,21-0,37$ & $1,70-3,40$ & $0,36-1,50$ & $1,16-2,28$ & $0,55-0,96$ & $0,07-0,17$ & $13,26-19,13$ & \\
\hline $\begin{array}{l}\text { Centropomus } \\
\text { undecimalis }\end{array}$ & $0,04-0,093$ & ND & $0,43-0,75$ & $15,23-35,13$ & $0,23-0,60$ & $1,73-2,03$ & ND & $4,13-8,90$ & \\
\hline Elops saurus & $0,60-0,95$ & $0,11-0,20$ & $0,91-1,40$ & $8,13-10,12$ & $0,53-0,86$ & $0,42-0,83$ & $0,09-0,19$ & $17,30-20,03$ & Presente \\
\hline Mugil curema & $0,04-0,060$ & $0,11-0,32$ & $1,76-3,01$ & $5,13-7,96$ & $0,96-1,30$ & $0,17-0,29$ & $0,08-0,14$ & $15,3-18,132$ & investigación \\
\hline Mugil gaimardianus & $0,03-0,063$ & $0,17-0,29$ & $1,63-2,90$ & $10,12-14,36$ & $1,11-1,80$ & $0,20-0,36$ & $0,14-0,28$ & $10,3-18,13$ & \\
\hline Mugil liza & $0,041-0,060$ & $0,03-0,09$ & $1,12-1,36$ & $7,32-9,63$ & $0,48-0,70$ & ND & $0,18-0,23$ & $20,12-28,72$ & \\
\hline P. schmitti & $0,026-0,080$ & $0,09-0,17$ & $7,13-10,12$ & $15,36-20,13$ & $18-22,12$ & $0,16-0,50$ & $0,18-0,31$ & $17,13-25,90$ & \\
\hline
\end{tabular}


Cuantificación de las concentraciones de metales pesados en peces de Unare, Anzoátegui, Venezuela / Márquez, A. y col.

que la fuerte intervención que presenta la laguna de Unare está contribuyendo a la acumulación de metales como el zinc en los tejidos de los peces y camarones. De no ser controlada debidamente esta intervención, conllevará a un completo deterioro ambiental de las especies que habitan este ecosistema, lo que se verá reflejado en la condiciones socio-económicas de las poblaciones aledañas a la misma, que sustentan su economía en la explotación de la laguna.

\section{CONCLUSIONES}

En el agua de la laguna de Unare las concentraciones de los metales pesados evaluados fueron bajas, observándose las máximas concentraciones durante las horas nocturnas, probablemente por la degradación en horas de la noche de la materia orgánica. En el sedimento, los valores sobrepasan los niveles considerados como contaminantes, lo cual pone en evidencia el grave deterioro ecológico que presentan los sedimentos de este importante ecosistema. En las especies ícticas, se determinaron discrepancias en el contenido de los diferentes en cada género y especies evaluadas, quizás originado por el tipo de alimentación de las especies y en segundo lugar a una progresiva bioacumulación del metal. Se determinó un contenido mayor de los metales, en los individuos de una misma especie (C. spixii), que habitan dentro de la laguna con respecto a las que habitan fuera de ella, sugiriendo que, la bioacumulación de los metales pudiera estar ocurriendo debido al mayor tiempo de retención de las aguas dentro de la laguna y al impacto ecológico existente en los sedimentos. Esta intervención antropogénica que presenta la laguna ha conllevado a que, las especies que se alimentan del lecho de la laguna presenten concentraciones altas de metales como el zinc en sus tejidos. Por lo observado, de no ser controlada la intervención existente en la laguna de Unare, esta alteración conllevará a un completo deterioro ambiental de las especies que habitan este ecosistema, lo que a futuro repercutirá en las condiciones socio-económicas de las poblaciones aledañas a la laguna, que sustentan su economía en la explotación de la misma.

\section{AGRADECIMIENTO}

Los autores agradecen al Consejo de Investigación de la UDO por el financiamiento otorgado para la presente investigación a través de los proyectos: Cuantificación de las concentraciones de metales pesados en tejidos de peces y crustáceos de la laguna de Unare, estado Anzoátegui. (C.I-5-1801-1081/02). A FUNDACITE Anzoátegui por el financiamiento del proyecto.

\section{REFERENCIAS BIBLIOGRÁFICAS}

[1] ANDRADE, J.; MARTINS, C.; CHARZEDDINE, L.; MARTìNEZ, G, Metales pesados en el poliqueto tubícula Americomphis magna (Andrew, 1981) (Annelida: Polichaeta). Saber. 9 (1):12-16.1997.
[2] ARIAS, A.; GAMBOA, N.; GARCÍA, J. Vanadium levels in gonads of white mullet (Mugil curema) in the Cariaco Gulf, Venezuela. Zoot.Trop. 19 (2): 165-172. 2001.

[3] BIDDIGER, G.; GLOSS, S. The importance of tropic transfer in the bioaccumulation of chemical contaminants in aquatic ecosystems. Resid. Rev. 91: 103-145. 1984.

[4] BEGUM, A.; AMIN, N.; KANEKO, S.; OHTA, K.: "Selected elemental composition of the muscle tissue of three species of fish, Tilapia nilotica, Cirrhina mrigala and Clarius batrachus, from the fresh water Dhanmondi Lake in Bangladesh". Food. Chem. 93 (3): 439-443. 2005.

[5] BOADA, M. Efectos de la temperatura sobre la acumulación y depuración de metales pesados (Cobre, Zinc y Cadmio) en Mugil curema (Piscis: Mugilidae). Inst. Oceanogr. Univ. Oriente. Tesis de Grado. 91 pp. 1984.

[6] BRIAN, W.; LANGSTON, J. Bioavility, accumulation and effects of heavy metals in sediments with special reference to United Kigdom estuaries: A review. Environ. Poll. 76: 89-13. 1992

[7] BOLTON, J.; STEHR, C.; BOYD, D.; BURROWS, D.;TKALIN, A.; LISHAVSKAYA, T. Organic and trace metal contaminants in sediments and English sole tissues from Vancouver Harbour, Canada. Mar. Environ. Res. 57: 19-36. 2003.

[8] CABRAL, H.; COSTA, M.; SALGADO, P. Does the Tagus estuary fish community reflect environmental changes? Clim Res. 18: 119-126. 2001.

[9] CHEN, MH.; CHEN, YC. Bioaccumulation of sedimentbound heavy metals in Grey Mullet, Liza macrolepis. Mar. Poll. Bull. 39 (1-12):239-44. 1999.

[10] DUAN, Y.; GUTTMAN, S.I.; ORIS, J.T.; BAILER, A.J. Genotype and toxicity relationships among Hyalella azteca: I. Acute exposed to metals or low pH. Environ. Tox. Chem. 19: 1414-1421. 2000.

[11] EISLER, R. Zinc hazards to fish, wildlife, and invertebrates: a synoptic review. U.S. Fish Wildl. Serv. Biol. Rep. 10 pp. 1993.

[12] ELBAZ-POULICHET, F.; GARNIER, J.; GUAN, M.; MARTIN, J.; THOMAS, A. The conservative behavior of trace metals ( $\mathrm{Cd}, \mathrm{Cu}, \mathrm{Ni}$ and $\mathrm{Pb})$ and as in the surface plume of stratified estuaries: Example of the Rhöne River (France). Estuar. Coast. and Shelf. Sci. 42: 280-310. 1996

[13] FERMíN, I. Estudio Geoquímico de la laguna de Unare, Estado Anzoátegui, Venezuela. Inst. Oceanogr. Univ. Oriente. Tesis de Grado. 106 pp. 2002.

[14] FUENTES, M. Condiciones geoquímicas de los sedimentos superficiales de la Laguna de Chacopata, Edo. 
Sucre, Venezuela. Inst. Oceanogr. Univ. Oriente. Tesis de Grado. 113 pp. 1998.

[15] GAAD, G.; GRIFFITHS, A. Microorganisms and heavy metals toxicity. Microb. Ecol. 4: 303-317. 1987.

[16] Gamboa, B.; Bonilla, J. Distribución de metales (Fe, Mn, $\mathrm{Cu}, \mathrm{Zn}$ ) en sedimentos superficiales de la cuenca Tuy-Cariaco. Bol. Inst. Oceanogr. Univ. Oriente. 22 (1-2): 103-110. 1983.

[17] Gamboa, B.; Bonilla, J.; Cedeño, G. Concentración de algunos metales pesados en sedimentos superficiales de la Bahía de Pozuelos y áreas adyacentes, Estado Anzoátegui. Venezuela. Bol. Inst. Oceanogr. Univ. Oriente. 25 (1-2): 233-240. 1986.

[18] GREENBER, A. Analysis of suspended metals. In: Standard Methods for the Examination of Water and Wastewater. $18^{\text {th }}$ Ed. (APHA-AHWA. USA). 3060 pp. 1992.

[19] GUERRA, A.; MARÍN, G. Algunos aspectos biológicos y pesqueros del lebranche (Mugil liza) en la laguna de Unare, estado Anzoátegui, Venezuela. Zoot. Trop. 20 (3): 287-305. 2002.

[20] HOGSTRAND, C.; WILSON, R.; POLGAR, D.; WOOD, C. Effects of zinc on the kinetics of branchial calcium uptake in freshwater rainbow trout during adaptation to waterborne zinc. J. Exper. Biol. 186: (1) 55-73.1994.

[21] LANDING, W.; LYONS, W.; OREM, W. Nutrient cycling and the biochemistry of $\mathrm{Mn}, \mathrm{Fe}$, and $\mathrm{Zn}$ in jelly fish; lake, Palao. Limnol. Oceanograf. 36: 515-525. 1992.

[22] LÓPEZ, F. Estudio Geoquímico de la laguna de Píritu, Estado Anzoátegui, Venezuela. Inst. Oceanogr. Univ. Oriente. Tesis de Grado. 109 pp. 2002.

[23] LORENZ, S.; FRANCESE, M.; SMITH, V.; FERRERO, E. Heavy metals affect the circulating haemocyte number in the shrimp Palaemon elegans. Fish. Shellfish. Immunol. 11 (6):459-72. 2001.

[24] MAGO-LECCIA, F. Contribución a la sistemática y ecología de los peces de la laguna de Unare, Venezuela. Bull.Mar.Sci. 15 (2):274-330. 1965.

[25] MARÍN, G. Ictiofauna y pesquerías de la laguna de Unare, estado Anzoátegui, Venezuela. Acta Biol. Venez. 20 (3):61-92. 2000.

[26] MZIMELA H; WEPENER, V.; CYRUS, D. Seasonal variation of selected metals in sediments, water and tissues of the groovy mullet, Liza dumerelii (Mugilidae) from the Mhlathuze Estuary, South Africa. Mar. Pollu. Bull.(46): 659-676. 2003.

[27] MORRIS, A.; BALE, A. Effect of rapid precipitation of dissolved $\mathrm{Mn}$ in river waters on estuarine $\mathrm{Mn}$ distributions. Nat. 229: 303-327. 1979.
[28] OKUDA, T.; GÓMEZ, J.; BENÍTEZ, A.; GARCÍA, A. Condiciones hidrográficas de la laguna de Unare y río Unare. Bol. Inst. Oceanogr. Univ. Oriente. 4(1) 61-108. 1965a.

[29] OKUDA, T.; GÓMEZ, J.; BENÍTEZ, A.; GÓMEZ, J. Características químicas de los sedimentos de la laguna y río Unare. Bol. Inst. Oceanogr. Univ. Oriente. 4(1):109-123. 1965b.

[30] PAULSON, A.; SHARACK, B.; ZDANOWICZ, V. Trace metals in ribbed mussels from Arthur Kill, New York/New Jersey, USA. Mar. Poll. Bull. 46:139-152. 2003.

[31] PAULY, D.; YANEZ-ARANCIBIA, A. Fisheries in coastal lagoons. En: Coast. Lagoon Proces. K.Kjerfve (Ed). Elsevier Oceanography Series.60. 377-399pp. 1994.

[32] PLASKETT, D.; POTTER, J. Heavy metals concentration in the muscle tissue of 122 species of teleost from Cockburn Sound, Western Australia. Austr. J. Freswater. Res. 30: 607-616. 1979.

[33] RAMÍREZ, I.; ROA M, P. Generalidades sobre las lagunas costeras de Venezuela. En: Manejo y aprovechamiento acuícola de lagunas costeras en América Latina y el Caribe. Proyecto AQUILA II. Programa Cooperativo Gubernamental. GCP/RLA/102/ITA. México. 330pp.1994.

[34] REDPATH, J.K. Growth inhibition and recovery in mussels (Mytilus edulis) exposed to low copper concentrations. J. Mar. Biol. Ass. U.K. 65: 421-431. 1985.

[35] RODRÍGUEZ-SIERRA, C.; JIMÉNEZ, B. Trace metals in striped mojarra fish (Diapterus plumieri) from Puerto Rico. Mar. Poll. Bull. 44: 1039-1045.1990. 2002.

[36] ROSS, K.; COOPER, N.; BIDWELL, J.R.; ELDER, J. Genetic diversity and metal tolerance of two marine species: a comparison between populations from contaminated and reference sites. Mar. Poll. Bull. 44: 671-679. 2002.

[37] SADIQ, M. Heavy metals. In: Toxic metal chemistry in marine environments. Marcel Dekker, Inc., New York, 390 pp. 1992.

[38] SALAZAR, J.; BONILLA, J.; GAMBOA, B. Metales pesados y materia orgánica en los sedimentos superficiales de la laguna Las Marites. Bol. Inst. Oceanogr. Univ. Oriente. 25 (1-2): 137-154. 1986.

[39] SCELZO, M. Toxicidad del cobre en larvas nauplii del camarón comercial Artemesia longinaris Bate (Crustacea, Decapoda, Penaeidae). Invest. Mar. Valparaíso. 25: 177-185. 1997.

[40] SENIOR, W.; CASTAÑEDA, J. Evaluación ambiental de las bahías de Bergantín, Pozuelos y Barcelona, ubicadas en las costas del Edo. Anzoátegui. Informe final. PDVSA. 133 pp. 1997. 
Cuantificación de las concentraciones de metales pesados en peces de Unare, Anzoátegui, Venezuela / Márquez, A. y col.

[41] SENIOR, W.; CASTAÑEDA, J.; MARTíNEZ, G. Estudio oceanográfico y calidad de agua y sedimentos nororiente de Venezuela: caso del sistema lagunar Unare-Píritu. Informe. Inst. Oceanogr. Univ. Oriente.70 pp. 1999.

[42] SHAHADAT H, M.; AHMED K, Y. Trace metals in Penaeid shrimp and Spiny lobster from the Bay of Bengal Scie. Asia. 27: 165-168. 2001.

[43] SHCUMATCHER, M.; DOMINGO, J.; LLOBET, J.; CORBELLA, J. Variations of heavy metals in water, sediments and biota from the Delta of the Ebro River, Spain. J. Environ. Sci. and Health. 30 (6):1361-1372. 1995.

[44] SOKAL, R.; ROHLF, J. The principles and practice statistics in biological research. In: Biometry W. H. Freeman and Company. USA.776 pp. 1969

[45] SUNDA, W.G.; LEWIS, G.A. Effect of complexation by natural organic ligands on the toxicity of copper to a unicellular algae, Monochrysis lutheri. Limnol. Oceanogr. 23 (5): 870-876. 1978.

[46] UNTERSTEINER, H.; GRETSCHE,G.; PUCHNER, T.; NAPETSCHNIG, S.; KAISER, H. Monitoring Behavioral Responses to the Heavy Metal Cadmium in the Marine Shrimp Hippolyte inermis Leach (Crustacea: Decapoda) with Video Imaging. Zool. Studies. 44 (1): 71-80. 2005.

[47] USERO, J.; IZQUIERDO, C.; MORILLO, J.; GRACIA, I. Heavy metals in fish (Solea vulgaris, Anguilla anguilla and Liza aurata) from salt marshes on the southern At- lantic coast of Spain. Environ. Internat. 29: 949-956. 2003.

[48] VERRENGIA-GUERRER, N:, KESTEN, E. Levels of heavy metals in biota from the La Plata River. Environ. Toxic. And Water Qual. 8: 335-344. 1993.

[49] VIALE-RIGO, M. Distribución y caracterización espectral de los hábitats del Flamenco (Phoenicopterus ruber ruber) y del Coro Coro Rojo (Eudocimus ruber) en las lagunas costeras de Tacarigua, Unare y Píritu, usando imágenes de satélites Landsat TM T.E.G. Facultad de Ciencias. UCV. 92 pp. 1992.

[50] WOOD, C.; VAN VLEET, E. Cooper, cadmium and zinc in the liver, kidney and muscle tissues of bottlenose dolphins (Tursiops truncates) stranded in Florida. Mar. Poll. Bull. 32 (12): 886-889. 1996.

[51] YILMAZ, A. Levels of heavy metals ( $\mathrm{Fe}, \mathrm{Cu}, \mathrm{Ni}, \mathrm{Cr}, \mathrm{Pb}$ and $\mathrm{Zn}$ ) in tissue of Mugil cephalus and Trachurus mediterraneus from Iskenderun Bay, Turkey. Environ. Res. 92: 277-281. 2003.

[52] ZDANOWICZ, V.; FINNERAN, T.; KOTHE, R. Digestion of fish tissue and atomic absorption analysis of trace elements. In: Lauenstein, G., Cantillo, A. (Eds.). Sampling and Analytical Methods of the National Status and Trends Program: National Benthic Surveillance and Mussel Watch Program 1984-1992. NOAA Technical Memorandum NOS ORCA 71. National Oceanic and Atmospheric Administration, Silver Spring, MD. 31-51 pp. 1993. 